\title{
Seletividade do halosulfuron-methyl aplicado na dessecação antes da semeadura da cultura do algodoeiro
}

\author{
Renata L. M. da Silva ${ }^{1}$, Augusto G. F. Costa ${ }^{2} \&$ Valdinei Sofiatti $^{3}$ \\ ${ }^{1}$ CBPEX. João Pessoa, PB. E-mail: renatalmsilva@gmail.com \\ ${ }^{2}$ Embrapa Algodão. Campina Grande, PB. E-mail: augusto.costa@embrapa.br (Autor correspondente) \\ ${ }^{3}$ Embrapa Algodão. Campina Grande, PB. E-mail: valdinei.sofiatti@embrapa.br
}

Palavras-chave:

herbicida

sulfonilureia

tolerância

Gossypium hirsutum

\begin{abstract}
R E S U M O
Objetivou-se, neste trabalho, avaliar a seletividade do herbicida halosulfuron-methyl para a cultura do algodoeiro quando aplicado na dessecação antes da semeadura. Dois experimentos foram conduzidos em condições de casade-vegetação em delineamento inteiramente casualizado com quatro repetições. Os tratamentos corresponderam a quatro períodos entre a aplicação do herbicida e a semeadura $(0,7,14$ e 21 dias) e uma testemunha sem aplicação. Os solos utilizados como substrato em cada experimento foram classificados como arenoso e francoargilo-arenoso. As avaliações realizadas foram: altura de plantas aos 7, 14, 21 e 28 dias após a emergência (DAE); diâmetro do caule, área foliar, volume de raízes, massa seca de parte aérea e raízes aos 28 DAE. Foi possível concluir que o halosulfuron-methyl aplicado até 14 dias antes da semeadura não é seletivo ao algodoeiro.
\end{abstract}

\section{Key words:}

herbicide

sulfonylurea

tolerance

Gossypium hirsutum

\section{Selectivity of halosulfuron-methyl applied in desiccation before seeding of cotton crop}

\begin{abstract}
A B S T R A C T
The aim of this study was to evaluate the selectivity of the herbicide halosulfuron-methyl in cotton when applied in desiccation before seeding. Two trials were conducted under green-house conditions in a completely randomized design with four replications. The treatments corresponded to four periods between herbicide application and seeding $(0,7,14$ and 21 days) and a control without application. The soils used as substrate in each experiment were classified as sandy and sandy clay loam. The evaluations made were: plant height at 7, 14, 21 and 28 days after emergence (DAE); stem diameter, leaf area, root volume, dry mass of aerial parts and roots at 28 DAE. It was possible to conclude that halosulfuron-methyl applied up to 14 days before sowing was not selective to cotton.
\end{abstract}

\section{INTRODUÇÃ̃o}

O cultivo do algodoeiro tem grande importância social e econômica em mais de 80 países cuja fibra produzida é largamente utilizada na indústria têxtil (Dutt et al., 2004; Inoue et al., 2013). Para que a cultura expresse o máximo potencial produtivo é necessário o controle dos fatores limitantes, entre os quais se destacam aqueles decorrentes da presença de plantas daninhas (Yamashita et al., 2008). A reconhecida sensibilidade do algodoeiro à interferência das plantas infestantes pode reduzir a produtividade em mais de 90\% (Freitas et al., 2003), além de dificultar e onerar a colheita e o beneficiamento, bem como depreciar a qualidade da fibra (Azevedo et al., 2008).

Entre as plantas daninhas que infestam a cultura do algodoeiro a tiririca (Cyperus rotundus L.) é considerada uma das espécies mais agressivas e danosas, com larga amplitude ecológica (Beltrão \& Azevêdo, 1994), sendo também destacada como sério problema em áreas irrigadas (Azevedo et al., 1994). Adicionalmente, Arruda et al. (2005) mencionam que o controle difícil dessa espécie resulta em aumentos significativos no custo de produção do algodoeiro.

Para evitar a interferência das plantas daninhas na cultura do algodoeiro o controle químico é o principal método utilizado (Dan et al., 2011). Entretanto, são poucas as opções de herbicidas seletivos para a cultura (Guerra et al., 2011). Para o controle de tiririca, o trifloxysulfuron-sodium é a principal alternativa, pois pode ser aplicado em área total após a semeadura. Conforme Oliveira Júnior (2011), este herbicida pertence ao grupo químico das sulfonilureias e possui, como mecanismo de ação, a inibição da enzima acetolactato sintase. A morte das plantas ocasionada pelo mesmo resulta de eventos que ocorrem em virtude da inibição dessa enzima e da produção de aminoácidos de cadeia ramificada. Mesmo sendo utilizado na cultura do algodoeiro o trifloxysulfuron-sodium possui registro para controle de tiririca apenas na cultura da cana-de-açúcar a 22,5 g i.a. ha ${ }^{-1}$. Esta dose é muito superior à tolerada pelo algodoeiro $\left(7,5 \mathrm{~g}\right.$ i.a. ha $\left.{ }^{-1}\right)$, a qual é recomendada apenas quando a cultura apresenta quatro folhas (MAPA, 2013). Quando aplicado nas fases iniciais de desenvolvimento, o mesmo pode causar injúrias na cultura 
(Freitas et al., 2006a,b) o que tem feito com que os agricultores reduzam a dose, tornando o controle ainda mais deficitário. Por outro lado, caso o controle ocorra tardiamente pode haver maior interferência de plantas daninhas na fase inicial de desenvolvimento da cultura.

Outro herbicida do grupo das sulfonilureias com o mecanismo de ação de inibição da enzima acetolactato sintase (ALS), que apresenta elevada eficácia de controle para tiririca e outras ciperáceas, é o halosulfuron-methyl (Vitelli et al., 2010). Apesar disto, este herbicida está registrado para aplicação em pós-emergência somente na cultura da cana-de-açúcar (MAPA, 2013). De acordo com os resultados obtidos por Souza et al. (2001), o halosufuron-methyl apresentou, quando utilizado no algodoeiro, menores efeitos tóxicos à cultura quando aplicado antes da semeadura indicando a possibilidade de novos estudos de seletividade. A aplicação de halosufuron-methyl na modalidade denominada "dessecação" ou "manejo" poderia ser uma estratégia para reduzir previamente a infestação das plantas daninhas pois se sabe que os dessecantes atualmente utilizados apresentam baixa eficiência de controle da tiririca. Por outro lado e de acordo com Wehtje et al. (2006), o halosufuronmethyl possui efeito sobre esta espécie não somente pela absorção via foliar mas também pela atividade residual no solo; como exemplo, Walters \& Young (2010) constaram maior nível de controle de plantas daninhas [Digitaria ischaemum (Schreb. ex Shweig) Schreb. ex Muhl e Amaranthus retroflexus L.] e produtividade de abóbora (Curcubita pepo L.) quando o clomazone+ethalfluralin foi associado ao halosufuron-methyl em aplicação de pré-emergência, antes da semeadura.

Um dos fatores relevantes que podem afetar a tolerância das culturas ao halosufuron-methyl é sua persistência no ambiente edáfico cuja degradação é maior com o aumento da temperatura e redução do $\mathrm{pH}$ do solo, sendo também influenciada pela umidade e textura o que proporciona, ao herbicida, meia-vida variando entre 7 e 98 dias (Dermiyati \& Yamamoto, 1997). Na solução do solo as moléculas de herbicidas tendem a atingir equilíbrio entre a fase sorvida e a que permanece na solução; entretanto, a absorção pelas plantas, a eficácia e o transporte dependem, em grande parte, do equilíbrio entre os processos de sorção e dessorção. A sorção das sulfonilureias varia em função do conteúdo de matéria orgânica, $\mathrm{pH}$, textura e mineralogia dos solos (Oliveira et al., 2005). Rocha et al. (2013) consideram que existem poucos estudos sobre o comportamento de herbicidas em solos tropicais e que os resultados dessas pesquisas são de grande importância para fazer recomendações seguras do ponto de vista técnico e ambiental. A persistência do herbicida no solo também influencia o período necessário entre a aplicação e a semeadura visando minimizar os possíveis efeitos fitotóxicos à cultura a ser implantada.

Para a cultura do algodoeiro as pesquisas voltadas à seletividade dos herbicidas favorecem a ampliação de alternativas ou estratégias de controle de plantas daninhas sobremaneira das espécies frequentes e de maior dificuldade de controle. Objetivou-se, então, com este trabalho, avaliar a seletividade do herbicida halosulfuron-methyl para a cultura do algodoeiro quando aplicado na dessecação antes da semeadura.

\section{Material e Métodos}

Dois experimentos com a cultura do algodoeiro foram conduzidos em condições de casa-de-vegetação localizada nas coordenadas $7^{\circ} 13^{\prime} 20^{\prime \prime}$ S e $35^{\circ} 54^{\prime} 14^{\prime \prime}$ W; para cada ensaio foi utilizado um substrato que correspondeu a solos originários das camadas aráveis (0 a $20 \mathrm{~cm}$ ) das localidades de Barbalha (CE) e Lagoa Seca (PB), classificados como Argissolo Vermelho e Neossolo Regolítico psamítico solódico (EMBRAPA, 1999).

As análises químicas e textural dos solos foram realizadas conforme descrito por EMBRAPA (1997), no Laboratório de Solos e Nutrição de Plantas da Embrapa Algodão e no Laboratório de Irrigação e Salinidade, pertencente à Universidade Federal de Campina Grande, respectivamente cujos resultados estão apresentados na Tabela 1 .

Os solos foram peneirados em malha de $2 \mathrm{~mm}$, secados à sombra, adubados com $10 \mathrm{~kg}$ de superfosfato simples e $100 \mathrm{~g}$ de ureia por $\mathrm{m}^{-3}$ de solo, os quais foram utilizados para preencher recipientes (vasos) de $2 \mathrm{~L}$ de capacidade constituindo-se nas parcelas experimentais.

Os dois experimentos foram instalados em delineamento inteiramente casualizado, com quatro períodos $(0,7,14$ e 21 dias) entre a aplicação do herbicida halosufuron-methyl e a semeadura, além de uma testemunha sem aplicação totalizando 5 tratamentos com 4 repetições. Para manutenção da umidade adequada nos recipientes a partir do primeiro dia de aplicação, foi realizada uma irrigação diária correspondente a $5 \mathrm{~mm}$ de precipitação, por meio de um sistema composto por microaspersores com acionamento pré-programado por meio de um "timer".

O herbicida halosufuron-methyl foi aplicado diretamente no solo úmido antes da semeadura na dose de $112,5 \mathrm{~g}$ i. a. ha ${ }^{1}$, conforme registro no Ministério da Agricultura, Pecuária e Abastecimento (MAPA) para o controle de Cyperus rotundus $\mathrm{L}$. na cultura da cana-de-açúcar (MAPA, 2013). Um pulverizador costal foi utilizado a pressão constante $\operatorname{com} \mathrm{CO}_{2}$, munido de barra com quatro pontas de pulverização de jato plano

Tabela 1. Características físico-químicas dos solos utilizados nos experimentos

\begin{tabular}{|c|c|c|c|c|c|c|c|c|c|c|c|c|c|c|c|c|}
\hline \multicolumn{13}{|c|}{ Características químicas } & \multicolumn{4}{|c|}{ Características físicas } \\
\hline \multirow{2}{*}{$\begin{array}{l}\text { Origem } \\
\text { do solo }\end{array}$} & $\begin{array}{c}\mathrm{pH}-\mathrm{H}_{2} \mathrm{O}^{1} \\
1: 2,5\end{array}$ & $\mathrm{Ca}^{+2}$ & $\mathrm{Mg}^{+2}$ & $\mathrm{Na}^{+}$ & $\mathbf{K}^{+}$ & S & $\mathrm{H}+\mathrm{Al}$ & $T$ & $\mathrm{Al}^{+3}$ & \multirow{2}{*}{$\begin{array}{l}\mathbf{V} \\
\%\end{array}$} & \multirow{2}{*}{$\begin{array}{c}P \\
\mathrm{mg} \mathrm{dm}^{-3}\end{array}$} & \multirow{2}{*}{$\begin{array}{l}\text { M.O. } \\
\text { g kg-1 }^{-1}\end{array}$} & Areia & Silte & Argila & \multirow{2}{*}{$\begin{array}{c}\text { Classificação } \\
\text { textural }\end{array}$} \\
\hline & \multicolumn{9}{|c|}{$\mathrm{mmol}_{\mathrm{c}} \mathrm{dm}^{-3}$} & & & & \multicolumn{3}{|c|}{ Granulometria (\%) } & \\
\hline Barbalha & 6,9 & 97,6 & 55,3 & 1,6 & 7,6 & 162,1 & 18,2 & 180,3 & ND & 89,9 & 11,9 & 20,7 & 53,60 & 24,51 & 21,89 & Franco-argilo-arenoso \\
\hline L. Seca & 6,1 & 14,4 & 5,4 & 0,4 & 1,2 & 21,4 & 15,7 & 37,1 & ND & 57,7 & 11,3 & 8,8 & 84,80 & 9,41 & 5,79 & Arenoso \\
\hline
\end{tabular}

${ }^{1} \mathrm{pH}_{2} \mathrm{O}$ - pH em água; $\mathrm{Ca}^{+2}$ - Cálcio; $\mathrm{Mg}^{+2}$ - Magnésio; $\mathrm{Na}^{+}$- Sódio; $\mathrm{K}^{+}$- Potássio; S - Soma de bases; H+Al - acidez potencial; $\mathrm{T}$ - Capacidade de troca catiônica; Al+3 - Alumínio; V - Saturação de bases; $\mathrm{P}$ - fósforo; MO - Matéria orgânica 
antideriva 11002 , espaçadas a $0,5 \mathrm{~m}$ entre si, posicionadas a 0,5 $\mathrm{cm}$ de altura do alvo, com consumo de $200 \mathrm{~L}^{\text {de calda ha }}{ }^{-1}$; as aplicações ocorreram nos diferentes momentos correspondentes aos períodos antes da semeadura.

A cultivar utilizada de algodoeiro foi a BRS 286 cujas sementes foram tratadas previamente com a mistura comercial dos fungicidas carboxina + tiram $\left(200+200\right.$ g i. a. $\left.\mathrm{L}^{-1}\right)$ e o inseticida imidacloprido (600 g i. a. $\mathrm{L}^{-1}$ ), ambos na dose de 5 $\mathrm{mL} \mathrm{kg}{ }^{-1}$. Todos os tratamentos foram semeados no mesmo dia, com três sementes por vaso a $3,0 \mathrm{~cm}$ de profundidade sendo o desbaste realizado 5 dias após a emergência das plântulas para permanência de uma planta por vaso. Durante o período experimental as parcelas foram mantidas livres da presença de plantas daninhas por meio de controle manual para evitar o efeito de interferência das mesmas sobre o desenvolvimento das plantas de algodoeiro.

Aos 7, 14, 21 e 28 dias após a emergência (DAE), foram feitas avaliações da altura das plantas $(\mathrm{cm})$ obtida a partir do colo até a inserção da gema apical por meio de régua graduada; aos 28 DAE foram avaliados o diâmetro do caule, a área foliar, a biomassa seca da parte aérea, o volume e a massa seca do sistema radicular. O diâmetro do caule foi mensurado no colo das plantas, rente ao solo utilizando-se um paquímetro digital. A área foliar foi obtida por estimativa a partir das dimensões foliares baseadas no método descrito por Monteiro et al. (2005), utilizando-se de régua graduada para as medições de todas as folhas de cada planta. A biomassa seca foi obtida por secagem do material vegetal em estufa de ventilação forçada de ar, a $65^{\circ} \mathrm{C}$ até alcançar massa constante; em seguida foram determinadas a massa de parte aérea e as raízes em balança semianalítica $\mathrm{O}$ volume do sistema radicular foi determinado com base na metodologia descrita por Silva et al. (2006), na qual as raízes são lavadas em água corrente e colocadas em uma proveta graduada com volume de $100 \mathrm{~mL}$, contendo 50 $\mathrm{mL}$ de água e se determina, ao se adicionar as raízes, o volume de água deslocado, sendo este valor equivalente ao volume ocupado pelas mesmas.

Os dados foram submetidos à análise de variância pelo teste $\mathrm{F}$ e as médias comparadas pelo teste Tukey a 0,05 de probabilidade.

\section{Resultados e Discussão}

Verificou-se que as maiores reduções na altura das plantas em solo arenoso, em relação a testemunha, ocorreram nas aplicações a 0 DAS, seguidas das diminuições observadas com a aplicação aos 7 DAS (Tabela 2). Em termos percentuais, a redução constatada com a semeadura ao 0 DAS chegou a $66 \%$ aos 14 DAE, sendo reduzida para $52 \%$ aos 28 DAE. Na aplicação aos 7 DAS os efeitos mais drásticos na altura de plantas foram detectados aos 7 DAE (39\%), sendo reduzidos gradativamente até os 28 DAE quando a diminuição nessa característica correspondeu a $27 \%$. As aplicações do herbicida halosufuronmethyl aos 14 e 21 DAS também promoveram reduções significativas na altura das plantas, semelhantes às ocorridas com a aplicação aos 7 DAS. Na literatura há escassez de dados
Tabela 2. Efeito de época de aplicação do halosufuronmethyl sobre a altura do algodoeiro semeado em solo arenoso aos 7, 14, 21 e 28 dias após a emergência

\begin{tabular}{lcccc}
\hline Tratamento/ & \multicolumn{4}{c}{ Altura (cm) $\mathbf{- ~ D A E ~}$} \\
\cline { 2 - 5 } \multicolumn{1}{c}{ Aplicação } & $\mathbf{7}$ & $\mathbf{1 4}$ & $\mathbf{2 1}$ & $\mathbf{2 8}$ \\
Sem aplicação & $10,00 \mathrm{C}$ & $13,37 \mathrm{c}$ & $16,00 \mathrm{~b}$ & $18,50 \mathrm{c}$ \\
O DAS & $3,75 \mathrm{a}$ & $4,50 \mathrm{a}$ & $5,87 \mathrm{a}$ & $8,87 \mathrm{a}$ \\
7 DAS & $6,12 \mathrm{ab}$ & $8,50 \mathrm{~b}$ & $11,50 \mathrm{~b}$ & $13,50 \mathrm{~b}$ \\
$14 \mathrm{DAS}$ & $6,25 \mathrm{~b}$ & $10,12 \mathrm{~b}$ & $13,37 \mathrm{~b}$ & $15,75 \mathrm{bc}$ \\
$21 \mathrm{DAS}$ & $7,50 \mathrm{~b}$ & $11,50 \mathrm{bc}$ & $14,50 \mathrm{~b}$ & $16,87 \mathrm{bc}$ \\
F & $16,66^{*}$ & $20,70^{*}$ & $13,71^{*}$ & $16,17^{*}$ \\
CV (\%) & 16,60 & 15,42 & 17,30 & 12,62 \\
DMS & 2,43 & 3,23 & 4,63 & 4,05 \\
\hline
\end{tabular}

DAS - Dias antes da semeadura; DAE - Dias após a emergência; Médias seguidas de mesma letra na coluna não diferem significativamente entre si a 0,05 de probabilidade pelo teste Tukey. *Significativo a 0,05 de probabilidade; NsNão significativo

a respeito do tempo necessário entre a aplicação e a semeadura para a minimização da fitointoxicação do halosufuron-methyl em culturas sensíveis. Lynn et al. (2007) avaliaram o efeito residual da aplicação em cultura antecessora em solos com baixos teores de argila (franco-arenosos) e matéria orgânica $(0,8 \%)$, nos quais constataram redução no crescimento da parte aérea de hortaliças (abóbora, espinafre e brócolis) embora Grey et al. (2007) tenham verificado tolerância de abóbora, berinjela, pepino e repolho ao mesmo herbicida quando aplicado no cultivo anterior em solos com a classificação textural areia franca, com teor de argila de $4 \%$ e de matéria orgânica entre 0,9 e 1,3\%. Apesar da semelhança entre os solos quanto aos baixos teores de argila e matéria orgânica, em ambos os trabalhos, as doses de halosufuron-methyl foram menores que a utilizada no presente estudo: 18 a 54 g i.a. ha ${ }^{-1}$ e 27 g i.a. ha ${ }^{-1}$, respectivamente; além disto, os períodos entre as aplicações dos herbicidas e a semeadura das hortaliças citadas foram no mínimo de 105 dias, bem superiores aos utilizados no presente trabalho, com $\mathrm{o}$ algodoeiro.

Para as demais características de crescimento (diâmetro do caule, área foliar, volume de raízes, massa seca da parte aérea e raízes) (Tabela 3), a aplicação realizada no mesmo dia da semeadura (0 DAS) em solo arenoso promoveu reduções que corresponderam a $36,60,62,74$ e $76 \%$, respectivamente. A

Tabela 3. Efeito de época de aplicação do halosufuronmethyl sobre o diâmetro do caule, área foliar, volume do sistema radicular, massa seca de parte aérea e raízes do algodoeiro semeado em solo arenoso, aos 28 dias após a emergência

\begin{tabular}{|c|c|c|c|c|c|}
\hline \multirow{3}{*}{$\begin{array}{c}\text { Tratamento/ } \\
\text { Aplicação }\end{array}$} & \multirow{3}{*}{$\begin{array}{c}\text { Diâmetro } \\
\text { do caule } \\
(\mathrm{mm})\end{array}$} & \multirow{3}{*}{$\begin{array}{l}\text { Área } \\
\text { foliar } \\
\left(\mathrm{cm}^{2}\right)\end{array}$} & \multirow{3}{*}{$\begin{array}{c}\text { Volume } \\
\text { de raízes } \\
\left(\mathrm{cm}^{3}\right)\end{array}$} & \multicolumn{2}{|c|}{ Massa seca } \\
\hline & & & & P. aérea & Raízes \\
\hline & & & & \multicolumn{2}{|c|}{ (g) } \\
\hline Sem aplicação & $5,00 \mathrm{~b}$ & $270,00 \mathrm{c}$ & $9,25 \mathrm{~b}$ & $1,85 \mathrm{c}$ & $1,32 \mathrm{c}$ \\
\hline 0 DAS & $3,18 \mathrm{a}$ & $107,70 \mathrm{a}$ & $3,50 \mathrm{a}$ & $0,49 a b$ & $0,31 \mathrm{a}$ \\
\hline 7 DAS & $4,22 a b$ & $147,47 \mathrm{ab}$ & $6,00 a b$ & $0,90 a b$ & $0,54 a b$ \\
\hline 14 DAS & $4,06 a b$ & $257,38 \mathrm{c}$ & $7,25 \mathrm{~b}$ & $1,41 \mathrm{bc}$ & $0,60 a b$ \\
\hline $21 \mathrm{DAS}$ & $5,20 \mathrm{~b}$ & 234,08 bc & $7,50 \mathrm{~b}$ & $1,29 b c$ & $0,74 \mathrm{~b}$ \\
\hline $\mathrm{F}$ & $5,50 *$ & $11,13^{*}$ & 7,37 * & $10,63^{*}$ & $19,86^{*}$ \\
\hline CV (\%) & 15,83 & 21,14 & 23,44 & 26,53 & 23,85 \\
\hline DMS & 1,50 & 93,88 & 3,43 & 0,69 & 0,53 \\
\hline
\end{tabular}

DAS - Dias antes da semeadura; DAE - Dias após a emergência; Médias seguidas de mesma letra na coluna não diferem significativamente entre si a 0,05 de probabilidade pelo teste Tukey. *Significativo a 0,05 de probabilidade; Ns Não significativo 
aplicação realizada aos 7 DAS também resultou em redução de área foliar (45\%) e massa seca de parte aérea (51\%), para as quais não foi possível constatar diferenças em relação ao tratamento de 0 DAS. A massa seca de raízes foi a única característica reduzida em todas as épocas de aplicação do halosufuron-methyl, com maior efeito ao 0 DAS, em relação aos 21 DAS. Desta forma, verifica-se que o efeito negativo do halosufuron-methyl nas características da parte aérea do algodoeiro foi influenciado provavelmente pela expressiva redução de crescimento do sistema radicular, em especial quando o herbicida foi aplicado aos 0 e 7 DAS. Verificou-se, em geral, que a aplicação do halosufuron-methyl em um período maior que 14 dias antes da semeadura proporcionou menor redução no crescimento das plantas, mesmo no solo arenoso. É provável que a degradação do herbicida que ocorre neste período, tal como a sorção nos coloides do solo, reduz consideravelmente a quantidade disponível para absorção radicular pela cultura do algodoeiro minimizando os efeitos de fitointoxicação.

Para o experimento realizado em solo franco-argiloarenoso, o crescimento em altura do algodoeiro (Tabela 4) foi afetado negativamente pela aplicação de halosufuron-methyl quando as semeaduras ocorreram aos 0, 7 e 14 dias após a aplicação do herbicida. Em termos percentuais médios, essas aplicações diminuíram a altura das plantas em 42 e $38 \%$, quando as mesmas foram avaliadas aos 7 e 14 DAE, respectivamente; aos 21 DAE somente a aplicação feita por ocasião da semeadura manteve efeito negativo sobre a altura das plantas com redução de $35 \%$ nessa característica; mesmo assim, as plantas apresentaram recuperação aos 28 DAE uma vez que não se constataram diferenças entre os tratamentos.

Quanto às variáveis diâmetro do caule, área foliar e volume de raízes (Tabela 5) não houve interferência do halosufuronmethyl, independente da época em que o herbicida foi aplicado; todavia, as aplicações do herbicida aos 0 e 7 DAS afetaram a massa seca de parte aérea e raízes, as quais foram reduzidas, em média, 56 e $51 \%$, respectivamente, quando comparadas à testemunha.

Em trabalho realizado em solo de textura média, Souza et al. (2001) constataram redução na área foliar do algodoeiro quando o halosufuron-methyl foi aplicado a $112,5 \mathrm{~g}$ i. a. ha-1, independentemente da época de aplicação antes da semeadura.

Tabela 4. Efeito de época de aplicação do halosufuronmethyl sobre a altura do algodoeiro semeado em solo franco-argilo-arenoso, aos 7, 14, 21 e 28 dias após a emergência

\begin{tabular}{lcccc}
\hline \multicolumn{1}{c}{ Tratamento/ } & \multicolumn{4}{c}{ Altura $\mathbf{( c m )}$ - DAE } \\
\cline { 2 - 5 } \multicolumn{1}{c}{ Aplicação } & $\mathbf{7}$ & $\mathbf{1 4}$ & $\mathbf{2 1}$ & $\mathbf{2 8}$ \\
Sem aplicação & $8,50 \mathrm{~b}$ & $13,37 \mathrm{~b}$ & $16,62 \mathrm{~b}$ & 19,37 \\
O DAS & $5,00 \mathrm{a}$ & $7,50 \mathrm{a}$ & $10,87 \mathrm{a}$ & 13,75 \\
7 DAS & $5,50 \mathrm{a}$ & $8,50 \mathrm{a}$ & $13,00 \mathrm{ab}$ & 16,33 \\
14 DAS & $4,50 \mathrm{a}$ & $8,66 \mathrm{a}$ & $13,83 \mathrm{ab}$ & 16,83 \\
21 DAS & $5,83 \mathrm{ab}$ & $9,83 \mathrm{ab}$ & $14,83 \mathrm{ab}$ & 18,17 \\
F & $5,66^{\star}$ & $4,69^{\star}$ & $3,19^{*}$ & $1,02^{\text {ns }}$ \\
CV (\%) & 22,30 & 21,99 & 17,28 & 25,77 \\
DMS & 2,86 & 4,60 & 5,22 & --- \\
\hline
\end{tabular}

DAS - Dias antes da semeadura; DAE - Dias após a emergência; Médias seguidas de mesma letra na coluna não diferem significativamente entre si a 0,05 de probabilidade pelo teste Tukey. *Significativo a 0,05 de probabilidade; Ns Não significativo
Tabela 5. Efeito de época de aplicação do halosufuronmethyl sobre o diâmetro do caule, área foliar, volume do sistema radicular, massa seca de parte aérea e raízes do algodoeiro semeado em solo franco-argilo-arenoso, aos 28 dias após a emergência

\begin{tabular}{|c|c|c|c|c|c|}
\hline \multirow{3}{*}{$\begin{array}{l}\text { Tratamento/ } \\
\text { Aplicação }\end{array}$} & \multirow{3}{*}{$\begin{array}{l}\text { Diâmetro } \\
\text { do caule } \\
(\mathrm{mm})\end{array}$} & \multirow{3}{*}{$\begin{array}{l}\text { Área } \\
\text { foliar } \\
\left(\mathrm{cm}^{2}\right)\end{array}$} & \multirow{3}{*}{$\begin{array}{c}\text { Volume } \\
\text { de raízes } \\
\left(\mathrm{cm}^{3}\right)\end{array}$} & \multicolumn{2}{|c|}{ Massa seca } \\
\hline & & & & P. aérea & Raízes \\
\hline & & & & \multicolumn{2}{|c|}{ (g) } \\
\hline Sem aplicação & 4,93 & 318,41 & 5,00 & $2,59 \mathrm{~b}$ & $0,58 \mathrm{~b}$ \\
\hline 0 DAS & 3,69 & 252,66 & 2,66 & $1,12 \mathrm{a}$ & $0,26 \mathrm{a}$ \\
\hline 7 DAS & 4,91 & 249,12 & 5,00 & $1,17 \mathrm{a}$ & $0,31 \mathrm{a}$ \\
\hline 14 DAS & 4,84 & 306,57 & 4,00 & $1,76 a b$ & $0,43 a b$ \\
\hline 21 DAS & 4,75 & 254,41 & 4,22 & $1,75 a b$ & $0,38 a b$ \\
\hline $\mathrm{F}$ & $1,61^{\mathrm{ns}}$ & $0,76^{\text {ns }}$ & $2,54^{\mathrm{ns}}$ & $8,09 *$ & $8,71^{*}$ \\
\hline CV (\%) & 18,09 & 27,56 & 28,74 & 24,93 & 30,58 \\
\hline DMS & --- & --- & --- & 0,91 & 0,26 \\
\hline
\end{tabular}

DAS - Dias antes da semeadura; DAE - Dias após a emergência; Médias seguidas de mesma letra na coluna não diferem significativamente entre si a 0,05 de probabilidade pelo teste Tukey. *Significativo a 0,05 de probabilidade; Ns Não significativo

No presente trabalho observou-se diminuição da área foliar em decorrência da aplicação do herbicida no solo arenoso, da mesma forma como ocorreu com as demais variáveis de crescimento (altura, diâmetro do caule, volume de raízes, massa seca de parte aérea e raízes). Para o solo franco-argilo-arenoso foram constatadas diminuições, embora em número menor de características: altura, massa da parte aérea e raízes.

Essas diferenças observadas nos resultados obtidos com os diferentes solos podem ser explicadas pelas respectivas características físico-químicas que interferem na disponibilidade dos herbicidas e, consequentemente, na sua absorção pelas plantas pois, conforme Wehtje et al. (2006) o halosufuron-methyl também é absorvido pelas raízes, apesar da via principal ser a foliar. Vivian et al. (2007) mencionam que em solos com altos teores de argila, matéria orgânica ou ambos, em geral, se verifica maior adsorção e persistência dos herbicidas. Assim, o maior teor de matéria orgânica e argila no solo franco-argilo-arenoso, em relação ao solo arenoso do presente trabalho, pode justificar a menor fitotoxidez às plantas de algodoeiro como resultado da disponibilidade inferior do halosulfuron-methyl.

Conforme Oliveira \& Brighenti (2011) deve-se destacar, ainda, que a matéria orgânica, em virtude da sua alta capacidade de troca de cátions e da grande superfície específica, tem papel fundamental na adsorção de herbicidas sendo que sua influência nas propriedades físico-químicas passa a ser ainda maior nos solos tropicais, haja vista que, predominantemente, eles possuem minerais de argila de baixa atividade. Adicionalmente e segundo esses autores, mesmo os minerais 2:1, como vermiculita e montmorilonita, apresentam efeito pouco menor sobre a adsorção de herbicidas em relação à matéria orgânica. Grey \& McCullough (2012) reportam que os herbicidas do grupo das sulfonilureias, do qual faz parte o halosufuron-methyl, são fracamente adsorvidos pelos minerais de argila, mas possuem, em geral, atividade inversamente proporcional ao teor de matéria orgânica; a partir dessas informações e dos resultados obtidos é possível sugerir que a matéria orgânica pode ter sido o fator de maior influência nos níveis de fitointoxicação verificados nos 
solos estudados pois o solo franco-argilo-arenoso apresentou teor 2,4 vezes maior que o solo arenoso (Tabela 1); ainda assim, deve-se levar em consideração a interferência do teor de argila, pois foi 3,8 vezes maior para o solo de Barbalha em relação ao de Lagoa Seca.

Ao considerar o efeito do período entre a aplicação do herbicida e a semeadura, ainda é possível verificar, no trabalho de Souza et al. (2001), que as dessecações efetuadas aos 15 e 30 DAS do algodão, foram as que proporcionaram menor fitointoxicação, correspondendo a $14 \%$ de diminuição na área foliar na última avaliação ( 75 dias após a semeadura); entretanto, a aplicação aos 2 DAS correspondeu a $46 \%$ de redução nessa característica indicando que, quanto menor o período entre a aplicação e a semeadura maiores foram os danos ao algodoeiro. No presente estudo os níveis de interferência foram maiores principalmente para os menores períodos entre a aplicação e a semeadura, sobremaneira aos 0 e 7 dias. De maneira semelhante, Guerra et al. (2011) constataram maior fitointoxicação quando as semeaduras da planta indicadora (pepino) foram realizadas mais próximas da aplicação prévia de herbicidas utilizados no algodoeiro, também pertencentes ao grupo das sulfonilureias e inibidores da enzima ALS (tryfloxysulfuron-sodium ou pyriothiobac-sodium).

Com os resultados do presente trabalho verificou-se, em geral, que a aplicação do herbicida halosufuron-methyl visando ao controle de Cyperus rotundus L. não pode ser feita por ocasião da semeadura do algodoeiro uma vez que resultou em severa fitotoxidez. A aplicação com no mínimo 21 dias de antecedência à semeadura reduziu consideravelmente a fitointoxicação à cultura; no entanto, as características químicas e físicas dos solos devem ser levadas em consideração, uma vez que maiores teores de argila e matéria orgânica diminuem ainda mais a possibilidade de efeitos negativos sobre as plantas de algodoeiro. Em solos arenosos é prudente aumentar o período entre a aplicação e a semeadura do algodoeiro ou evitar o uso do herbicida halosufuron-methyl.

\section{Conclusão}

O halosulfuron-methyl aplicado até 14 dias antes da semeadura não é seletivo ao algodoeiro.

\section{Agradecimentos}

Ao Conselho Nacional de Desenvolvimento Científico e Tecnológico (CNPq), pela bolsa de iniciação científica (PIBIC) concedida ao primeiro autor.

\section{Literatura Citada}

Arruda, F. P.; Andrade, A. P; Beltrão, N. E. de M.; Pereira, W. E.; Lima, J. R. Viabilidade econômica de sistemas de preparo de solo e métodos de controle de tiririca em algodoeiro. Revista Brasileira de Engenharia Agrícola e Ambiental, v.9, p.481-488, 2005.
Azevedo, D. M. P.; Beltrão, N. E. de M.; Ferreira, A. C. B.; Leão, A. B.; Cardoso, G. D.; Vieira, D. J.; Nóbrega, L. B. Manejo de plantas daninhas. In: Beltrão, N. E. de M.; Azevedo, D. M. P. O agronegócio do algodão no Brasil. 2.ed. Brasília: Embrapa Informação Tecnológica, 2008. p.791-832.

Azevedo, D. M. P.; Beltrão, N. E. de M.; Nóbrega, L. B.; Santos, J. W. dos; Vieira, D. J. Período crítico de competição entre plantas daninhas e o algodoeiro anual irrigado. Pesquisa Agropecuária Brasileira, v.29, p.1417-1425, 1994.

Beltrão, N. E. M. de; Azevedo, D. M. P. Controle de plantas daninhas na cultura do algodoeiro. Brasília: Embrapa SPI, 1994. 154p.

Dan, H. A.; Barroso, A. L. L.; Oliveira Júnior, R. S.; Constantin, J.; Dan, L. G. M.; Braz, G. B. P.; Oliveira Neto, A. M.; D'Avila, R. P. Seletividade de clomazone isolado ou em mistura para a cultura do algodoeiro. Planta Daninha, v.29, p.601-607, 2011.

Dermiyati, S. K.; Yamamoto; I. Degradation of the herbicide halosulfuron-methyl in two soils under different environmental conditions. Journal of Pesticide Science, v.22, p.282-287, 1997.

Dutt, Y.; Wang, X. D.; Zhu, Y. G. Breeding for high yield and fibre quality in coloured cotton. Plant Breeding, v.123, p.145-151, 2004.

EMBRAPA - Empresa Brasileira de Pesquisa Agropecuária. Centro Nacional de Pesquisa de Solos. Manual de métodos de análise de solos. 2.ed. Rio de Janeiro: EMBRAPA, 1997. 212p.

EMBRAPA - Empresa Brasileira de Pesquisa Agropecuária. Centro Nacional de Pesquisa de Solos. Sistema brasileiro de classificação de solos. Brasília: Produção de Informação, 1999. 412p.

Freitas, R. S.; Berger, P. G.; Ferreira, L. R.; Cardoso, A. A.; Freitas, T. A. S.; Silva, A. A. Interferência de plantas daninhas na cultura do algodão. Ceres, v.50, p.367-381, 2003.

Freitas, R. S.; Ferreira, L. R.; Berger, P. G.; Silva, A. C.; Cecon, P. R.; Silva, M. P. Manejo de plantas daninhas na cultura do algodoeiro com s-metolachlor e trifloxysulfuron-sodium em sistema plantio convencional. Planta Daninha, v.24, p.311-318, 2006a.

Freitas, R. S.; Tomaz, M. A.; Ferreira, L. R.; Berger, P. G.; Pereira, C. J.; Cecon, P. R. Crescimento do algodoeiro submetido ao herbicida trifloxysulfuron-sodium. Planta Daninha, v.24, p.123-129, 2006b.

Grey, L. T; McCullough, P. E. Sulfonylurea herbicides' fate in soil: dissipation, mobility, and other processes. Weed Technology, v.26, p.579-581, 2012.

Grey, L. T; Webster, T. M.; Culpepper, S. Autumn vegetable response to residual herbicides applied the previous spring under low-density polyethylene mulch. Weed Technology, v.21, p.496-500, 2007.

Guerra, N.; Oliveira Júnior; R. S.; Constantin, J.; Oliveira Neto, A. M.; Santos, G.; Jumes, T. M. C. Persistência de trifloxysulfuron-sodium e pyrithiobac-sodium em diferentes tipos de solo. Planta Daninha, v.29, p.673-681, 2011. 
Inoue, M. H.; Oliveira Junior, R. S.; Ben, R.; Dallacort, R.; Sztoltz, C. L. Seletividade de herbicidas aplicados em préemergência na cultura do algodão. Ciência Agronômica, v.44, p.123-132, 2013.

Lynn, P. B. Shrefler, J. W.; Webber Iii, C. L.; Talbert, R. E.; Payton, M. E.; Wells, L. K.; Mcclelland, M. Injury potential from carryover of watermelon herbicide residues. Weed Technology, v.21, p.473-476, 2007.

MAPA - Ministério da Agricultura, Pecuária e Abastecimento. Agrofit. http://extranet.agricultura.gov.br/agrofit_cons/ principal_agrofit_cons. 12 Mar. 2013.

Monteiro, J. E. B. A.; Sentelhas, P. C.; Chiavegato, E. J.; Guiselini, C.; Santiago, A. V.; Prela, A. Estimação da área foliar do algodoeiro por meio de dimensões e massas das folhas. Bragantia, v.64, p.15-24, 2005.

Oliveira Júnior, R. S. Mecanismos de ação de herbicidas. In: Oliveira Júnior, R. S.; Constantin, J.; Inoue, M. H. Biologia e manejo de plantas daninhas. Curitiba: Omnipax Editora, 2011.p.141-192.

Oliveira, M. F.; Brighenti, A. M. Comportamento de herbicidas no ambiente. In: Oliveira Júnior, R. S.; Constantin, J.; Inoue, M. H. Biologia e manejo de plantas daninhas. Curitiba: Omnipax, 2011. p.263-304.

Oliveira, M. F.; Prates, H. T.; Sans, L. M. A. Sorção e hidrólise do herbicida flazasulfuron. Planta Daninha, v.23, p.101113, 2005.

Rocha, P. R. R.; Faria, A. T.; Borges, L. G. F. C.; Silva, L. O. C.; Silva, A. A.; Ferreira, E. A. Sorção e dessorção do diuron em quatro solos brasileiros. Planta Daninha, v.31, p.231-238, 2013.
Silva, M. T. H.; Martins, A. B. G.; Andrade, R. A. Enraizamento de estacas de pitaya vermelha em diferentes substratos. Caatinga, v.19, p.61-64, 2006.

Souza, L. S.; Martins, D.; Camposilvan, D., Velini, E. D.; Palma, V. Seletividade do halosulfuron isolado ou em mistura com glyphosate para culturas anuais. Planta Daninha, v.19, p.351-358, 2001.

Vitelli, J. S.; Madigan, B. A; Haaren, P. E. van. Control techniques and management strategies for the problematic Navua sedge (Cyperus aromaticus). Invasive Plant Science and Management, v.3, p.315-326, 2010.

Vivian, R.; Guimarães, A. A.; Queiroz, M. E. L. R.; Silva, A. A.; Reis, M. R.; Santos, J. B. Adsorção e dessorção de tryfloxysulfuron-sodium e ametryn em solos brasileiros. Planta Daninha, v.25, p.97-109, 2007.

Walters, S. A.; Young, B. G. Effect of herbicide and cover crop on weed control in no-tillage jack-o-lantern pumpkin (Curcubita pepo L.) production. Crop Protection, v.29, p.30-33, 2010.

Wehtje, G. R.; Gilliam, C. H.; Grey, T. L.; Blythe, E. K. Potential for halosulfuron to control eclipta (Eclipta prostrata) in container-grown landscape plants and its sorption to container rooting substrate. Weed Technology, v.20, p.361367, 2006.

Yamashita, O. M.; Mendonça, F. S.; Orsi, J. V. N.; Resende, D. D.; Kappes, C.; Guimarães, S. C. Efeito de doses reduzidas de oxyfluorfen em cultivares de algodoeiro. Planta Daninha, v.26, p.917-921, 2008. 